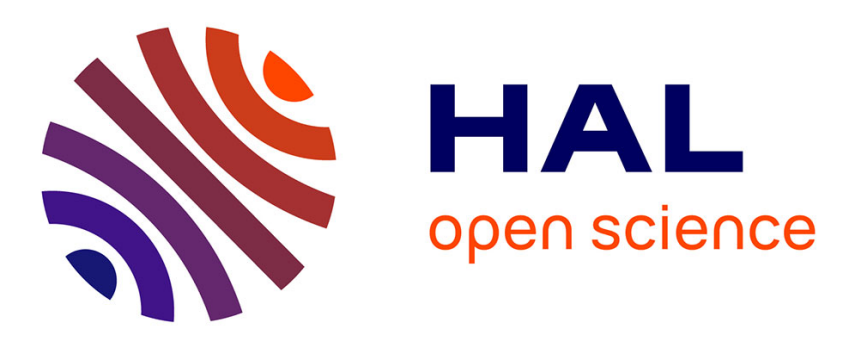

\title{
Influence of processing parameters on the tool and workpiece mechanical interaction during Friction Stir Welding
}

Sandra Zimmer, Laurent Langlois, Julien Laye, Jean-Claude Goussain, Patrick Martin, Régis Bigot

\section{To cite this version:}

Sandra Zimmer, Laurent Langlois, Julien Laye, Jean-Claude Goussain, Patrick Martin, et al.. Influence of processing parameters on the tool and workpiece mechanical interaction during Friction Stir Welding. International Journal of Material Forming, 2009, 2 (1), p. 299-302. 10.1007/s12289-0090496-7 . hal-00750735

\section{HAL Id: hal-00750735 \\ https://hal.science/hal-00750735}

Submitted on 12 Nov 2012

HAL is a multi-disciplinary open access archive for the deposit and dissemination of scientific research documents, whether they are published or not. The documents may come from teaching and research institutions in France or abroad, or from public or private research centers.
L'archive ouverte pluridisciplinaire HAL, est destinée au dépôt et à la diffusion de documents scientifiques de niveau recherche, publiés ou non, émanant des établissements d'enseignement et de recherche français ou étrangers, des laboratoires publics ou privés. 


\title{
Influence of processing parameters on the tool and workpiece mechanical interaction during Friction Stir Welding
}

\author{
S. Zimmer ${ }^{1}$, L. Langlois ${ }^{1}$, J. Laye ${ }^{2}$, J-C. Goussain ${ }^{2}$, P. Martin ${ }^{1}$, R. Bigot ${ }^{1}$ \\ ${ }^{1}$ Arts et Metiers ParisTech, LCFC, 4 rue Augustin Fresnel, 57070 METZ, France \\ ${ }^{2}$ Institut de Soudure, FSW Center, 2-4 rue Pilatre de Rozier, 57420 GOIN, France
}

\begin{abstract}
During Friction Stir Welding process, FSW, a tool / workpiece mechanical interaction is generated leading to forces and torques applied on the tool. These forces and torques are transmitted to the welding equipment impacting its technical requirements. This paper presents a forces and torques analysis according to the processing parameters on the welding at constant speed stage. The analysis was performed on the whole welding process windows, by varying one process parameter after the other. The goal of this work is to determine if and how the forces and torque could be reduced by working on the processing parameters. So, with lower forces and torque applied on the tool, the use of a standard and flexible welding equipment, allowing the welding of complex geometries, could be enabled.
\end{abstract}

KEYWORDS: Friction Stir Welding, Welding stage, Processing Parameters, Process forces and torque

\section{INTRODUCTION}

Friction Stir Welding (FSW) is an innovative welding process commonly known as being a solid state welding process [1]. This particularity gives it the availability to weld almost all types of aluminium alloys, even the one classified as non-weldable by fusion welding due to hot cracking and poor solidification microstructure in the fusion zone [2]. To perform FSW, a non-consumable rotating tool, made up of a shoulder and a pin, is inserted into the interface of two workpieces rigidly clamped. Once the shoulder in contact with the surface's workpieces, a constant down force is applied on the tool and is moved along the joint line, bounding the workpieces together. The processing parameters are chosen in order to ensure the energy input and the tool kinematics in order to achieve a defect-less weld. In consequence, during the whole welding process forces and torques are generated in the three directions, impacting the welding equipment requirements. Our research field is the industrialisation of the friction stir welding, in order to provide tools to industrials to qualify a FSW welding equipment or to define requirements for buying new equipements.

\section{NOMENCLATURE}

\section{$\mathrm{F}_{\mathrm{z}}[\mathrm{kN}] \quad$ Axial force}

$\mathrm{F}_{\mathrm{x}}[\mathrm{kN}] \quad$ Force in the travel direction

$\mathrm{F}_{\mathrm{y}}[\mathrm{kN}] \quad$ Force perpendicular to $\mathrm{F}_{\mathrm{x}}$

$\mathrm{C}_{\mathrm{z}}[\mathrm{Nm}] \quad$ Spindle Torque

$v_{\mathrm{a}}[\mathrm{mm} / \mathrm{min}] \quad$ Travel speed

$\mathrm{N}$ [tr/min] Tool rotational frequency

$\mathrm{E}_{\mathrm{n}}[\mathrm{J} / \mathrm{mm}] \quad$ Nominal energy, defined as been the total welding power divided by the travel speed.

\section{DEFINING THE CARACTERISTIC PARAMETERS}

The first step is to analyse the tool / workpiece mechanical interaction on the whole welding process. The objective is to determine the process and machine characteristic parameters. The Figure 1 presents the common forces and spindle torque evolution throughout Friction Stir Welding.

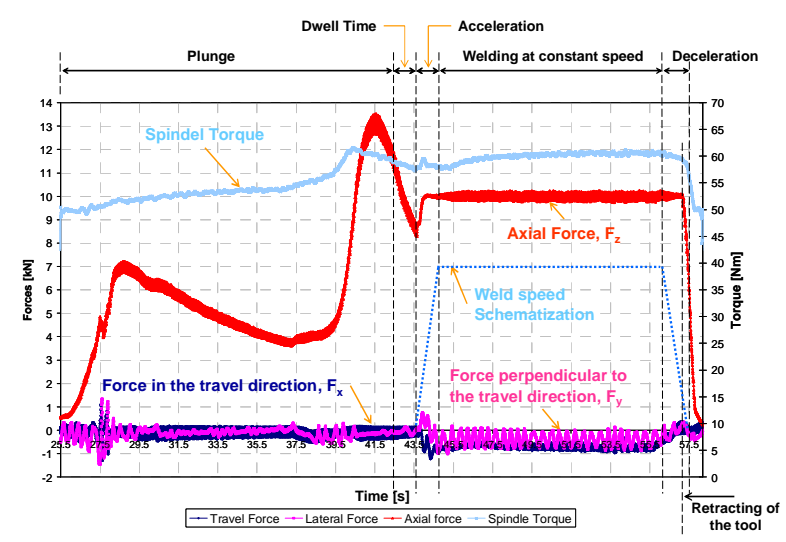

Figure 1: Visualization of the forces and torque applied on the tool during the FSW process

Zimmer and al [3] conclude that the forces and torque generated during the plunging and the welding at constant travel speed were characteristic for a static qualification of a FSW means of production. Therefore, these two welding stages should be investigated in order to analyze the influence of the processing parameters on the tool / workpiece mechanical interactions, Figure 2. The mechanical interactions are transmitted by the tool

S. ZIMMER -Arts et Métiers ParisTech Metz

4, rue Augustin Fresnel- 57070 Metz cedex 3

0033(0)683876021- sandra.zimmer@metz.ensam.fr 
to the welding equipment requiring a certain stiffness, forces and torques capacities. Therefore, one way to enable the use of a flexible and standard welding equipment, allowing the FSW of complex geometries, is to work on the processing parameters in order to reduce the load applied on the welding equipment while ensuring a good weld quality. Generally this type of equipment is identified as being limited in force capability and lack of stiffness [5].

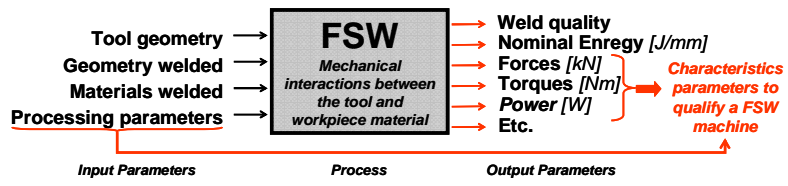

Figure 2: Relation between the input and the output parameters

This paper focuses on the tool kinematics and mechanical interaction produced during the welding at constant speed, the stage leading to the joint generation. The Figure 2 presents the tool kinematics and the mechanical interaction applied on the tool during the welding stage at constant travel speed.

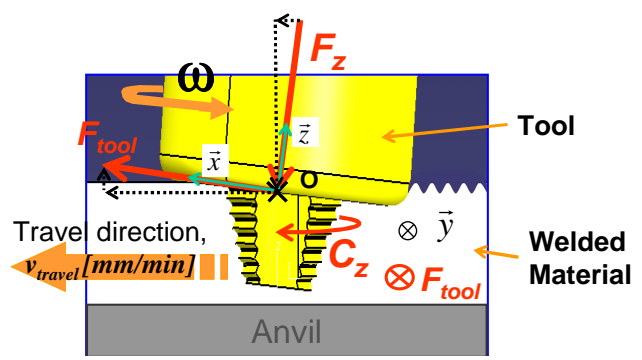

Figure 2: Tool / Workpiece mechanical interaction

The force applied by the tool on the workpiece is given by the equation (1).

$$
\vec{F}_{\text {tool/workpiece }}=F_{\text {tool }} \times \vec{x}+F_{\text {tool }} \times \vec{y}+F_{z} \times \vec{z}
$$

The equation (2) gives the momentum applied by the tool, on point $\mathrm{O}$, on the workpiece material. In the following study, the torque components $\mathrm{L}_{\mathrm{x}}$ and $\mathrm{L}_{\mathrm{y}}$ presented in the equation (2) is not taken into consideration and are assumed to be equal to zero.

$$
\vec{T}_{\text {tool/workpiece }, O}=L_{x} \times \vec{x}+L_{y} \times \vec{y}+C_{z} \times \vec{z}
$$

So, this paper will focus on the study of the influence of the welding processing parameters $\left(\mathrm{N}, v_{\mathrm{a}}, \mathrm{F}_{\mathrm{z}}\right)$ on the forces and torques generated without analyzing the plunging stage.

\section{EXPERIMENTAL PROCEDURE}

In order to analyse the influence of the processing parameters on the tool and workpiece mechanical interaction during the welding stage, each processing parameters were modified one after another. The processing parameters evolved so that the whole process window was covered. Therefore, all the tests led to sound welds, i.e. without internal or external defects. The Figure 3 presents the processing parameters and the analysed output parameters. The tilt angle was set up at $2.5^{\circ}$ and remains fixed for all the tests.

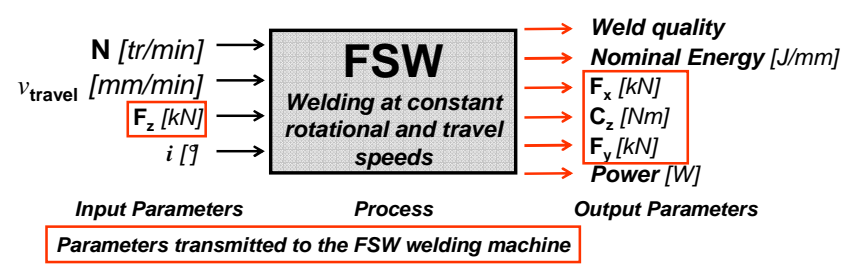

Figure 3: Relationship between the studied output parameters and the input parameters

In order to start the welding stage in the same initial thermo-mechanical conditions, the plunging and dwell processing parameters were set up identically for each welding tests. The welded length was $300 \mathrm{~mm}$. All the tests were performed in a $6 \mathrm{~mm}$ thick, 6000 aluminium alloy plate. The selected tool is a conventional tool, made of steel, with a concave shoulder and a cone-shape threaded pin. All the experiments were performed at the Institut de Soudure, on a MTS-ISTIR-10 Friction Stir Welder, a fully instrumented machine.

\section{RESULTS}

The experimental results will be decomposed into two case studies, analysing the output parameters $\mathrm{F}_{\mathrm{x}}, \mathrm{F}_{\mathrm{y}}, \mathrm{C}_{\mathrm{z}}$ and $\mathrm{E}_{\mathrm{n}}$ responses when:

- the axial force is evolving and $\mathrm{N}$ and $v_{\mathrm{a}}$ remains constant,

- $\quad \mathrm{N}$ and $v_{\mathrm{a}}$ are evolving, one after another, and $\mathrm{F}_{\mathrm{z}}$ remains at the same value

All the analysis has been performed on the steady state welding portion, i.e. when $\mathrm{C}_{\mathrm{z}}, \mathrm{N}$ and $v_{\mathrm{a}}$ remain constant.

\subsection{Evolution of the output parameters when $F_{z}$ is evolving}

The determined process windows, of the selected material, enables to evolve the axial force $F_{z}$ from 10 to $21.5 \mathrm{kN}$ for $\mathrm{N}$ and $v_{\mathrm{a}}$ remaining constant. The Figure 4 presents the spindle torque evolution over the axial force range. Surprisingly, as the axial force knows a $115 \%$ variation, the spindle torque evolves only of $8 \%$. So, an axial force increase does not imply an increase of the tool rotation resistance.

As the axial force applied is increasing it could be supposed that the required torque would become more important. This small torque evolution could be 
explained by a tangential stress applied on the tool limited by the material flow yield stress. Therefore, even if the normal force increases, as the material shear stress is reached, the torque does not know a significant increase. This type of material behaviour was also identified in hot forging. The total power needed to perform the welding operation is defined as being $C_{z} \cdot \omega$ [3], because the power related to the tool travel motion is negligible against the power developed for the tool rotation. Therefore, as $v_{\mathrm{a}}$ constant, the nominal energy also evolves from $8 \%$, Figure 4. The evolutions of $F_{x}$ and $F_{\mathrm{y}}$ are not significant as $\mathrm{F}_{\mathrm{z}}$ vary but their values always remained under $20 \%$ of $\mathrm{F}_{\mathrm{z}}$.

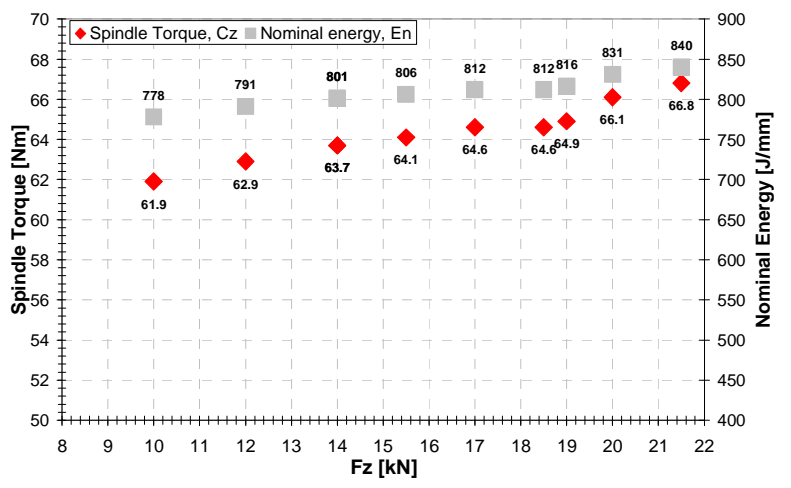

Figure 4: Spindle torque $C z$ and Nominal energy $E_{n}$ evolution as the axial force process range

\subsection{Evolution of the output parameters when $\mathbf{N}$ and $v_{\mathrm{a}}$ are evolving}

On the other hand, when $\mathrm{N}$ or $v_{\mathrm{a}}$ are varying, one after another, over the whole process windows, the torque and the forces $F_{x}$ and $F_{y}$ does know some evolution. The Figure 5 presents the spindle torque evolution when $\mathrm{N}$ and $v_{\mathrm{a}}$ are varying. It can be noted that, when the spindle frequency increases, the torque does know a significant decrease. A tool spindle frequency increase involves a higher material strain rate around the tool but also a frictional heat input increase. Both are leading to a heat input increase, described by the nominal energy Figure 6 , and consequently a material temperature increase generating a material viscosity decrease facilitating the tool rotation.

On the other side, the spindle torque doesn't seem to be sensitive to the travel speed increase, because an increase of $750 \%$ only involves a $6 \%$ torque increase. So it can be conclude that the material flow around the tool, related to the tool travel motion, isn't significant in the material heat input. Therefore, it can be noted that the torque is principally a function of the spindle frequency.

Therefore, it can be noted that the torque is principally a function of the spindle frequency.

With the previous conclusions, the nominal energy can be defined as being:

$$
E_{n}=\frac{\text { Power }}{v_{a}}=\frac{C_{z} \times \pi \times N}{30 \times v_{a}} \approx \frac{\pi}{30} \times \frac{f(N) \times N}{v_{a}}
$$

Therefore, when $\mathrm{F}_{\mathrm{z}}$ and $\mathrm{N}$ are set up as constant and $v_{\mathrm{a}}$ is varying, the equation (3) numerator remains constant because $\mathrm{C}_{\mathrm{z}}$ is not sensitive to variation of $v_{\mathrm{a}}$. So, in this case, the nominal energy is a function of $\left(1 / v_{\mathrm{a}}\right)$. The strong influence of $v_{\mathrm{a}}$ can be seen on the Figure 6. On the other hand, when $\mathrm{F}_{\mathrm{z}}$ and $v_{\mathrm{a}}$ are set up as constant and $\mathrm{N}$ is varying, the nominal energy will be influenced by the variation of $\mathrm{N}$ and the variation of $\mathrm{C}_{\mathrm{z}}$. So, the nominal energy is principally a function of $\mathrm{N}$ and $v_{\mathrm{a}}$.

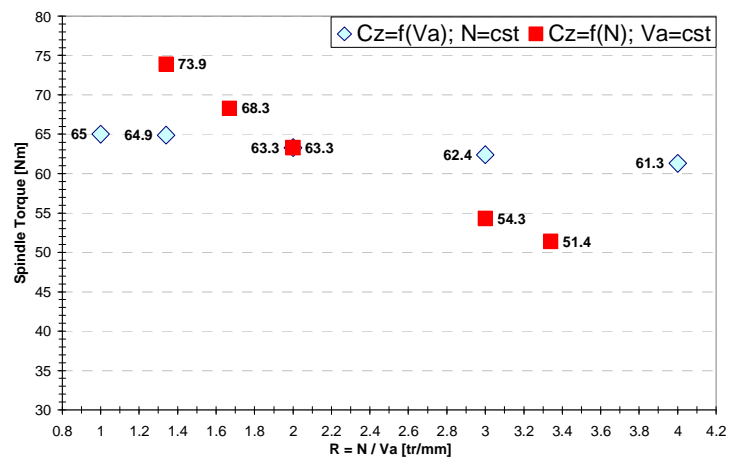

Figure 5: Evolution of the spindle torque according to $R$

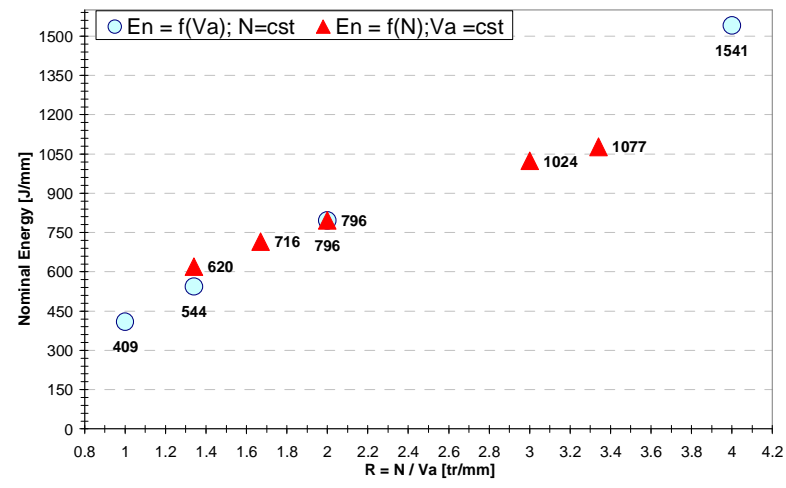

Figure 6: Nominal Energy, $E_{n}$, evolution according to $R$

On the other side, $F_{x}$ and $F_{y}$ doesn't know linear evolutions as $\mathrm{N}$ and $v_{\mathrm{a}}$ are varying independently, Figure 7 and Figure 8. This implies that their maximal or minimal values are not located at process windows extremity. It is interesting to study the transversal force responses as the travel speed decreases, for $\mathrm{N}$ remaining constant, generating a nominal energy increase. In a first time, as $\mathrm{R} \leq 2$, the transverse force $\mathrm{F}_{\mathrm{y}}$ decrease due to an increase of heat input generating a shear stress decrease around the pin. Then, even if the travel speed continues to decrease, the transverse force has a tendency to grow. This could be explained by a ration $\left(\mathrm{N} / v_{\mathrm{a}}\right)$ involving a higher material shearing speed and therefore an increase of the shear stress responsible of a $\mathrm{F}_{\mathrm{y}}$ increase. 
However, it can be noted on Figure 8 that the travel force, $\mathrm{F}_{\mathrm{x}}$, is very sensitive to variation of $v_{\mathrm{a}} . \mathrm{F}_{\mathrm{x}}$ is decreasing with a decrease of $v_{\mathrm{a}}$ and consequently an increase of $E_{n}$, at $\mathrm{N}$ constant. This travel force decrease could be explained by an increase of the plasticised zone in front of the pin, due to more heat input, facilitating the tool travel along the workpiece interface [4]. The results showed that $F_{x}$ and $F_{y}$ maximal values could reach $30 \%$ of the parameterized value $\mathrm{F}_{\mathrm{z}}$.

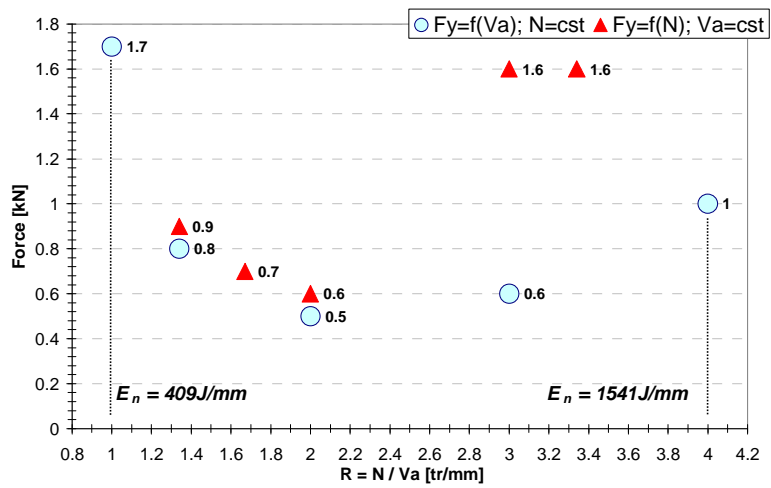

Figure 7: Evolution of the transverse force, $F_{y}$, according to $R$, for $N$ and $v_{\mathrm{a}}$ varying each after one other

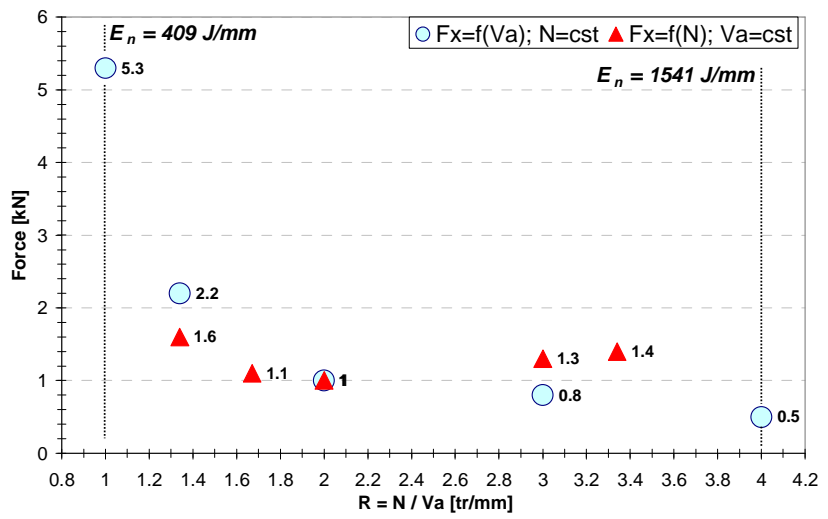

Figure 8: Evolution of travel force, $F_{x}$, according to $R$, for $N$ and $v_{\mathrm{a}}$ varying each after one other

\section{CONCLUSION AND FUTURE WORK}

The presented experimental results were obtained by the friction stir welding process window exploration. Therefore, the numerical results are depending on the used tool geometry, the welded material and thickness. The evolution of $F_{x}, F_{y}$ and $C_{z}$, according to the processing parameters, presented above are general material behaviour. These tendencies are probably the results of the combination of the strain rate increase and of the viscosity decrease due to the material temperature increase. Therefore, they should be applied for other tool geometries and welded material.

The results showed that the Friction Stir Welding resulting forces and torques, generated during welding, are be influenced by the input parameters, $\mathrm{N}, v_{\mathrm{a}}$ and $\mathrm{F}_{\mathrm{z}}$. Therefore it is not absurd to work on these processing parameters in order to reduce the load applied on the welding equipment.

The analysis showed that $\mathrm{C}_{\mathrm{z}}$ does not be sensitive to variation of $v_{\mathrm{a}}$ and $\mathrm{F}_{\mathrm{z}}$. For the tool and material chosen, for $\mathrm{N}$ and $v_{\mathrm{a}}$ set up as constant, $\mathrm{F}_{\mathrm{z}}$ knows a wide process range. This characteristic is interesting when the application should be performed on a standard flexible means of production, limited in force capacity, like an industrial robot. On the other side, $\mathrm{C}_{\mathrm{z}}$ and $\mathrm{F}_{\mathrm{x}}$ are very sensitive to variation of $\mathrm{N}$ and $v_{\mathrm{a}}$. In order to minimize their value, a high rotational speed and a low travel speed should be taken. This suggests that a compromise will probably to be made between weld quality and load transmitted to the welding equipment.

As mentioned before, two welding stages are characteristic for the static qualification of a FSW means of production. The welding stage was one of it. Therefore, the second one, the plunging, should be investigated in the same manner. Then, the plunging and welding processing parameters, allowing the use of means of production with limited forces capacities, can be chosen. Thus, the whole welding process will be defined for an industrial application. So this study shows that for application point of view it is necessary to control the interaction between manufacturing process and machine and in order to choice the manufacturing parameters.

\section{ACKNOWLEDGEMENT}

The authors would like to thanks the Region Lorraine and the Moselle department to financially support this research project and Daniel Strina for its technical support.

\section{REFERENCES}

[1] W.M. Thomas, E.D. Nicholas, J.C. Needham, M.G. Murch, P. Templemith, C.J. Dawes, Patent Application, No. 9125978.8 (December 1991).

[2] R.S Mishra, Z.Y. Ma, Friction Stir Welding and processing, Materials Sciences and Engineering R 50 (2005) I-78

[3] S. Zimmer, L. Langlois, J. Laye, J.-C. Goussain, P. Martin, R. Bigot, Methodology for qualifying a Friction Stir Welding equipment, Proceedings of the $7^{\text {th }}$ International Symposium on Friction Stir Welding 2008

[4] S. Sheiki, Herstellung und Bewertung der Umformbarkeit von reibrührgeschweissten Tailored Blanks aus Aluminiumlegierungen, $\mathrm{Ph}$. D Work, University of Duisburg-Essen - 2005

[5] M. Soron, FSW of high-strength aluminium alloys using and Industrial robot system: a feasibility study, $7^{\text {th }}$ International Symposium on Friction Stir Welding 2008 